\title{
Números y significaciones. La idealidad en la fenomenología incipiente de Husserl $^{1}$
}

\author{
José Manuel Chillón²
}

Recibido: 26 de junio de 2015 / Aceptado: 5 de julio de 2016

Resumen. La reflexión sobre los números y las significaciones es una buena muestra de cómo la fenomenología incipiente se sitúa en el terreno de la lógica pura. El artículo plantea que, para trazar una reflexión que no rasgue la personalidad filosófica de Husserl, lo ideal debe entenderse desde la perspectiva de trabajos posteriores. El artículo intenta ofrecer, tras los análisis iniciales de los números y de las significaciones (recogidos respectivamente tanto en sus obras primeras sobre matemática como en la I Investigación Lógica) las tesis sobre la idealidad en Husserl que, en nuestra opinión, detectan los aspectos fundamentales de la fenomenología a pesar del abandono posterior del realismo eidético.

Palabras Clave: ciencia estricta; ideal; lógica pura; números; significaciones; validez.

\section{[en] Numbers and meanings. Ideality in the incipient Husserl's phenomenology}

\begin{abstract}
The reflection on numbers and meanings are a good example of how the incipient phenomenology is in the realm of pure logic. The paper states that, due to ambiguities in these early works and in order to draw a reflection that does not tear the philosophical personality of Husserl, the thesis of the ideality be read from the perspective of later works. This paper reconstructs, from initial analysis of the numbers and meanings, the thesis of the ideality Husserl which, in our view, detect the fundamental aspects of phenomenology despite the subsequent abandonment of the eidetic realism.

Keywords: strict science; ideality; pure logic; numbers; meanings; validity.
\end{abstract}

Sumario. 1. Los números como objetos ideales: de la investigación psicológica a la fundamentación filosófica; 2. Las significaciones en Investigaciones Lógicas I; 3. Tesis sobre la idealidad en el Husserl de la fenomenología eidética; 4. Conclusión; 5. Referencias bibliográficas.

Cómo citar. Chillón, J.M. (2017): "Números y significaciones. La idealidad en la fenomenología incipiente de Husserl”, en Revista Anales del Seminario de Historia de la Filosofía 34 (1), 163-184.

\footnotetext{
1 Este artículo se enmarca dentro del Proyecto de Investigación del MINECO cuya referencia es FF1201563794-P

2 Departamento de Filosofía Universidad de Valladolid josemanuel@fyl.uva.es
} 


\section{Los números como objetos ideales: de la investigación psicológica a la fundamentación filosófica}

Husserl llega a la filosofía desde la singular influencia que sobre él ejerce el razonamiento matemático, en especial la aritmética. Los pilares que sustentarán la fenomenología se encuentran in nuce aquí, en la formación matemática inicial de Husserl: ${ }^{3}$ la existencia de un ámbito de objetividad distinto a la mera objetualidad fáctica, el carácter estricto del quehacer intelectual-científico y el papel de la subjetividad en el proceso de conocimiento así como en la capacidad para descubrir el ámbito estricto de los objetos puros. La fenomenología consistiría en la defensa de la estricta idealidad de objetos como las esencias y la imposibilidad de hacer filosofía sin tener en cuenta la vida consciente ante la que se abren todos estos objetos, la conciencia ante la que se dan las cosas mismas.

La matemática es la primera y la última de todas las ciencias (...) La matemática, como nos enseña la historia, consiguió por primera vez la tendencia a los laureles de la evidencia segura, aquí encontró por primera vez aquella aeterna veritas y aquellos métodos seguros del conocimiento que fueron meta ejemplar para toda ciencia y así seguirá siendo. ${ }^{4}$

Las matemáticas, pues, tienen algo que fascina al razonamiento filosófico. Platón quiso construir todo un sistema de pensamiento en el que los filósofos pudieran razonar como lo hacían los geómetras. Son estos los que conocen bien la diferencia entre las figuras geométricas ideales y los objetos reales. Una filosofía a salvo de las sombras cavernosas de la retórica sofística debería postular la existencia de un ámbito de autenticidad absoluta no contaminado por las doxai. Un ámbito, objeto del puro conocimiento, en el que estuvieran los conceptos que permitieran a los filósofos atribuir predicados a las cosas, esto es, definir. Nadie puede acceder a la Academia sin saber matemáticas. Evidente. No sólo porque la geometría enseñe a distinguir bien entre lo ideal y sus realizaciones concretas, sino porque el pensamiento discursivo sobre los objetos matemáticos, ya en el ámbito ontológico del mundo inteligible, entrena al filósofo a no tener que soñar con los principios porque los ve, a no necesitar las hipótesis porque puede intuir las ideas.

Para Descartes, las matemáticas son el modelo de conocimiento que deberá seguir la filosofía si quiere entrar en la senda de la fundamentación estricta. Sólo en las matemáticas encuentra Descartes la ciencia en la que no existe la distancia entre la seguridad subjetiva y la verdad objetiva. Sólo ella puede servir para construir el edificio del conocimiento desde un método que parta de la indubitabilidad de la evidencia y avance fecundamente en la determinación del conocimiento. Descartes - escribe Husserl- inaugura una filosofía enteramente nueva y "cambiando el estilo total de la filosofía, da una vuelta radical del objetivismo ingenuo al subjetivismo trascendental". ${ }^{5}$

3 Es la tesis, entre otros, de W. Biemel: "Para perseguir la génesis de la fenomenología, hay que remontarse bastante atrás, hasta el trabajo Philosophie der Arithmetik de 1891, o hasta la edición anterior del primer capítulo de este libro en su primera redacción aparecida en 1887, como trabajo de habilitación, con el título Über den Begriff der Zahl". Biemel, W. "Las fases decisivas del desarrollo de la filosofía de Husserl". En Husserl. Tercer Coloquio Filosófico de Royaumont, Buenos Aires: Paídós, 1968, pp. 35-67. De la cita, p. 8

4 Husserl, E. Studien zur Arithmetik und Geometrie. Texte aus den Nachlaß (1886-1901). La Haya: M. Nijhoff, 1986. Hua XXI, p. 216.

5 Husserl, E. Meditaciones cartesianas. Traducción de Mario Presas. Madrid: Tecnos, 2009, p. 7. En adelante $M C$. 
El recorrido husserliano parte de uno de los conceptos básicos de la matemática, el concepto de número. Los números pueden ser descritos de forma apodíctica y no empírica. Los números existen como objetos puros ideales. Resulta que después, cuando la fenomenología proponga como lema 'a las cosas mismas', estará reclamando un concepto de cosa más fundamental y radical que la pobre contingencia de los hechos donde los objetos se encuentran ya adornados y revestidos de múltiples interpretaciones especulativas. ${ }^{6}$ Los números y, como veremos enseguida, las significaciones, son algunas de estas cosas mismas.

El número es considerado como una multiplicidad de unidades, una multiplicidad formal que no puede tener como base los contenidos individuales sino el enlace colectivo (kollektive Verbindung) que se da entre esos contenidos individuales. Pero este enlace colectivo se da mediante un acto psicológico en el que se funda el concepto de número. La idea de multiplicidad (Vielheit) no se consigue simplemente abstrayendo los contenidos individuales sino describiendo cómo esos elementos particulares se unen en un todo. Importa pues el modo de unión. Ahora bien, ese modo de unión no es evidente a los sentidos, no puede comprobarse empíricamente sino que sólo puede describirse por reflexión. Es preciso entender el tipo de relación psíquica que consiste en prescindir de los contenidos para lograr ese concepto abstracto de pluralidad que es el número. Husserl se situaba así del lado de quienes propusieron fundar la lógica en la psicología. Según Derridá, al intentar describir, aún como psicólogo, el origen subjetivo y perceptivo del número sin borrar el sentido universal e ideal de los valores aritméticos, Husserl espera poder renovar la metafísica; los objetos ideales (y los números lo son) resultan producidos por actos subjetivos: "nos vemos obligados a decir que los números son producidos por el arte de enumerar (...) Los números son creaciones del espíritu, en la medida en que ellos constituyen resultados de actividades que ejercemos respecto de contenidos concretos". Además se encarga de añadir que lo que producen estas actividades subjetivas no son contenidos reales en el sentido de que tengan una existencia empírica que luego podamos verificar en el mundo, "sino peculiares conceptos de relación, siempre creados, nunca hallados ya listos en parte alguna". ${ }^{7}$ Se expresa aquí su inicial entusiasmo por el método axiomático que irá abandonando a medida en que su propósito de armonizar psicologismo y constructivismo se venga abajo. Los números son, pues, conceptos relacionales, son en la medida en que son producidos. ${ }^{8}$ La conexión colectiva - explica Husserl- es captada a partir de una reflexión sobre el acto psíquico sobre el que se origina la pluralidad. ${ }^{9}$ La importancia de los análisis psicológicos radica en que sólo ellos pueden abordar el problema del origen de los conceptos, de su génesis, de modo que la lógica no es más que un apartado de la psicología que se convierte así, siguiendo a Brentano, en la ciencia filosófica fundamental. La idea de la fundamentación psicológica de la lógica, tomada

6 Según Derrida, "la especulación metafísica inspiró a Husserl una desconfianza total”. Cfr. Derrida, J. La fenomenología y la clausura de la metafísica. Introducción a Husserl, Edición digital de Derrida en castellano, 2008, p. 1. Así el darse de las cosas mismas, es un darse en su pura desnudez (leibhaftig), libre de todo ropaje de interpretaciones posibles. "El método intuitivo concreto, pero también apodíctico de la fenomenología excluye toda aventura metafísica, todos los excesos especulativos”. Husserl, MC, p. 181.

Husserl, E. Über den Begriff der Zahl. Psycologische Analysen. Halle a. S.: Heynemann'sche Buchdruckerey (F. Beyer), 1887, p. 37

Biemel, p. 11

9 Husserl, Begriff der Zahl, p. 58 
fundamentalmente de J. Stuart Mill, resultó equivocada pero no la incipiente idea de que la génesis de los conceptos ideales habría de ser buscada en la conciencia.

Progresivamente se va consolidando su alejamiento del psicologismo ${ }^{10}$ al sugerir que la ligazón propia de los conjuntos no se basa exclusivamente en el acto colectivo psíquico; al retirar, bajo la influencia de Cantor, sus críticas a Frege; al reconocer el error que supone dar preferencia a los números enteros y no distinguir entre números finitos e infinitos o al considerar erróneo su capítulo sobre las definiciones de los números, entre otros. El abandono de los estudios de la matemática y la concentración en las cuestiones lógicas de fundamentación, sitúan a Husserl en los umbrales de la problemática filosófico-fenomenológica, como él mismo se encargará de explicar en el prólogo de Investigaciones Lógicas. El camino seguido personalmente por Husserl en su propósito radicalizante - es la tesis de Ovidio García Prada- se hace así patente: de la física a la matemática, de esta a la lógica, de aquí a la filosofía y, una vez encarrilado, a su definitiva versión fenomenológico-trascendental. ${ }^{11}$

Aparece aquí una idea nuclear de la fenomenología: para conocer la esencia de las cosas es preciso remontarse al origen de su significación en la conciencia, ¿no será esta la tesis capital del concepto fenomenológico de reducción? ${ }^{12}$ Esta propuesta, unida a la crítica posterior al psicologismo (consistente en atribuir el origen de los objetos ideales a procesos psíquicos empíricos omitiendo así su sentido ideal y su valor de universalidad) alumbrará enseguida la propuesta de que la significación no es una tarea de la constitución psicológica particular del ser humano, sino de una conciencia trascendental a cuyo descubrimiento y descripción se dirige la fenomenología. El acceso a la subjetividad debe hacerse pero no ya desde los estrechos márgenes de la psicología sino desde la lógica pura y el hallazgo de la absoluta necesidad de sus leyes.

La crítica a la psicología como ciencia fundamental se hace patente ya en Investigaciones Lógicas cuyo objetivo fundamental no es otro que liberar a las leyes lógico-formales, entre ellas las leyes de la aritmética, de explicaciones psicológicas partiendo de la concepción de la lógica heredada de Brentano por la cual la lógica tiene que estudiar las condiciones que toda teoría ha de reunir para ser ciencia. ${ }^{13} \mathrm{La}$

10 Para este diagnóstico sigo a García Prada, O. "La fundamentación de la matemática y la génesis de la metódica fenomenológico-reductiva”. Anales del Seminario de Historia de la Filosofía, vol. 6, 2, 1986, pp. 47-78. Nos referimos a pp. 62ss. Según San Martín, al rechazar de manera expresa el psicologismo, está rechazando también el antropologismo y la antropología como punto de partida de cualquier explicación en el sistema del saber. De esta manera, la fenomenología se situaba más allá de todo subjetivismo. Todo ello, fundamentalmente aderezado por la crítica de Heidegger, contribuye a forjar la imagen del Husserl convencional que insiste en el carácter no humano, por abstracto, del sujeto del que trata la fenomenología. San Martín, J. La nueva imagen de Husserl. Lecciones de Guanajuato. Madrid, Trotta, 2015, p. 31

11 García Prada, p. 51. Es lo que algunos autores han denominado el paso de la ideación (Ideation) a la idealización (Idealiserung).

12 "Fundamentalmente, la idea de reducción fenomenológica es una elaboración consecuente de la actitud reflexionante que Husserl había ya explicitado como decisiva en la Philosophie der Arithmetik” Biemel, p. 28. En el trabajo de García Prada, pp. 52ss, se establecen las conexiones entre la idea fundamental de reducción y los trabajos previos de Husserl. Y así como parece que la idea de reducir la matemática a la aritmética y esta al concepto de número es una mera coincidencia lexicográfica, no sucede lo mismo con el concepto de reducción que aparece en trabajos como el de su tesis doctoral Beiträge zur Theorie der Variations-rechnung cuyo objetivo es simplificar el método de comprobación en el campo del cálculo de las variaciones, a base de reducir los problemas de estas a los relativos de las ecuaciones diferenciales.

13 Husserl se da cuenta del fracaso de su proyecto fundacional en dos frentes. En el psicológico porque el naturalismo le impide concebir adecuadamente la génesis de las multiplicidades infinitas y las contradicciones lógicas que ellas contienen. En el frente lógico porque el estado defectuoso de su desarrollo bloquea el tema de 
crítica al psicologismo se va fraguando gracias a sus estudios sobre Leibniz, sobre la lógica de Lotze o sobre la Wissenschaftslehre de Bolzano. Lotze hablaba de verdades en sí acercándose a la idea de situar todo lo matemático y buena parte de la lógica tradicional en el reino de lo ideal. Bolzano, por su parte, alumbra la idea de conseguir una exposición del ámbito de las doctrinas puramente ideales en las que Husserl ve ya un esbozo de lo que llamará la lógica pura cuya idea fundamental es que sea posible una teoría de las teorías respecto de la cual todas las demás teorías fueran actualizaciones o pudieran ser deducidas de esa superteoría. ${ }^{14}$

En realidad, Husserl no puede ser tachado de idealista desde el momento en el que, por mucho que los números como ejemplo de objetos ideales se produzcan en la acción de contar, ello no conlleva que los sujetos puedan constituir arbitrariamente el sentido del objeto número, sino que los actos de constitución son subsidiarios de la esencia de los objetos, de las cosas mismas. ${ }^{15}$ Lo mismo sucederá con la diferencia entre las significaciones como especies y los actos de dar significación que no dejan de ser vivencias concretas sometidas al flujo temporal. Así pues, los actos psíquicos abren al fenomenólogo a la esencia de los objetos, permiten que los objetos sean representados. Husserl se hará cada vez más consciente de la importancia que tiene la aclaración permanente de esta distancia entre lo real y lo ideal para que se observe el tránsito entre Philosophie der Arithmetik, insistente en el aspecto productivo del acto psicológico de enlace por el cual los números eran constituidos (sin que esto signifique un tipo de existencia mundana verificable empíricamente) y la fenomenología eidética que postula la evidencia intuitiva de las esencias. ${ }^{16}$

Pronto es consciente de que el psicologismo ${ }^{17}$ es una forma de escepticismo. Desde la psicología es imposible fundamentar las condiciones más universales del conocimiento. La universalidad y necesidad que exige toda ciencia que quiera ser estricta no puede quedar garantizada por las leyes de la psicología que no pueden ir más allá de una mera generalización inductiva de datos empíricos cuya validez está vinculada a ciertas condiciones fácticas. La crítica al psicologismo es, a su vez, el reconocimiento de un ámbito de universalidad y necesidad absolutas como el de las esencias, objetos ideales, ámbito al que pertenecen los objetos lógicos, distinto al ámbito de lo real-fáctico. El siguiente paso, en palabras de Husserl, consiste en

\footnotetext{
la esencia racional de las ciencias deductivas. Puede verse una explicación más amplia de esto en Rizo-Patrón, R. "Génesis de las Investigaciones lógicas de Husserl: una obra de irrupción”. Signos Filosóficos, 7, 2002, pp. 221-244.

14 Cfr. Husserl, E. Investigaciones Lógicas. Traducción de Manuel G. Morente y José Gaos. Madrid: Alianza, 2011. En adelante, $I L, \S 60$. De hecho, una de las críticas a la lógica formal es que se ha vuelto cómplice de la falta de comprensión de la universalidad del ser y de su fundamental unidad propia de las ciencias. Una lógica que, "en vez de mantener la mirada fija en su situación histórica y convertirse en una teoría pura y universal de la ciencia, se convirtió ella misma en una ciencia especial”. Husserl, E. Lógica formal y lógica trascendental. México: UNAM, 1962, p. 8.

15 "Si no hay seres inteligentes... entonces estas posibilidades ideales quedan sin realidad que las cumpla; la aprehensión, el conocimiento o la conciencia de la verdad... no se realiza en este caso nunca en ninguna parte. Pero toda verdad en sí sigue siendo lo que es, conserva su ideal”. Husserl, $I L$, p. 159.

16 Años más tarde aclarará lo que trató de hacer: "En mi Philosophie der Arithmetik logré fijar la atención en lo formal y obtuve una primera comprensión de su sentido. Por más inmadura que fuera esta obra primeriza, representaba, empero, un primer intento de lograr claridad sobre el sentido propio y original de los conceptos fundamentales de la teoría de conjuntos y de la teoría de los números (...) Para expresarlo en mi forma de hablar ulterior: era una investigación fenomenológico-constitutiva." Husserl, Lógica formal, pp. 88-89.

17 En el que todavía incurre la filosofía trascendental de Kant al preguntarse por las condiciones de posibilidad del factum de la ciencia y vincular la universalidad y necesidad del conocimiento a estructuras fácticas concretas del sujeto empírico responsables de la objetividad del conocimiento.
} 
"llegar a comprender claramente qué sea lo ideal en sí y su relación con lo real; cómo lo ideal puede estar en relación con lo real; cómo puede ser inherente a este y llegar así a ser conocido". ${ }^{18}$ La matemática, al descubrir al joven Husserl el radicalismo del saber al modo como lo experimentó Descartes, quizá tenga alguna palabra para la desolación intelectual en la que se encuentra nuestra indigente situación. No en vano, Husserl, en la Introducción a las Meditaciones cartesianas se pregunta si no será la causa de esta crisis aquella que tiene que ver con la pérdida de las fuerzas impulsoras que subyacieron a las Meditaciones de Descartes quedando en el olvido "el espíritu del radicalismo propio de la autorresponsabilidad filosófica". ${ }^{19}$

Con todo, matemática y filosofía no son lo mismo. La diferencia básica reside en que los problemas que suscita la fundamentación matemática no pueden resolverse sino desde la filosofía. La investigación lógica de la aritmética formal y de la teoría de las multiplicidades -explica Husserl en los Prolegómenos - le deparó tantas dificultades que fue la que le forzó a consideraciones que rebasaban la estricta esfera matemática hacia una teoría general de los sistemas deductivos, esto es, hacia la lógica. ${ }^{20}$

\section{Las significaciones en Investigaciones Lógicas I}

En el universo de la lógica pura no sólo hay números. De lo que se trata ahora es de descubrir cómo Husserl completa el tránsito de las matemáticas a la filosofía con la reflexión sobre el lenguaje que le invita a pensar que las significaciones también forman parte del terreno de lo ideal recién descubierto por la fenomenología. La relación entre el acto concreto de contar y los números sirven de modelo para explicar la relación entre el acto de decir, de enunciar y las significaciones. Unos $\mathrm{y}$ otras son intemporales y unos y otras advierten al joven Husserl de distintos grados de idealidad que ahora todavía no son tematizados y que generan algunas ambigüedades si no se aclara que la significación de un objeto particular no es una especie del mismo tipo que la significación de las objetividades lógicas (siempre de una universalidad superior) ${ }^{21}$ como no tiene el mismo índice de idealidad el número que cualquiera de las leyes de la aritmética. Porque el tratamiento filosófico de los números y de las significaciones incardinan al fenomenólogo en el ámbito propio de la lógica pura, el análisis del acto de contar y de las expresiones concretas lo sitúan en los umbrales de ese terreno de lo ideal hasta ahora falto de mirada filosófica. Hemos visto ya lo primero, vayamos pues al estudio fenomenológico de las expresiones para reconstruir desde ahí, cómo Husserl toma conciencia de estar tratando con otro tipo de esas cosas mismas, de esas verdades que una vez captadas son independientes del ser humano, sin salir del terreno de la lógica pura que delimita con una radicalidad sin par el positivismo de las ciencias empíricas tan en boga, de la tarea infinita de la filosofía.

El lenguaje es el instrumento del conocimiento, del pensar en general. El análisis del lenguaje permite estudiar la significación de las proposiciones. Se distinguen

Husserl, $I L, \S 51$.

Husserl, $M C$, p. 9.

Cfr. Husserl, IL, p. 21

21 Debo esta observación a la atenta lectura que el profesor Javier San Martín hizo de una versión previa de este trabajo. Agradezco enormemente su maestría. 
en la expresión ${ }^{22}$ la parte física o el signo sensible compuesto por el complejo vocal articulado, y un cierto conjunto de vivencias psíquicas que, enlazadas por asociación a la expresión, hacen que esta se refiera a algo. Observa Husserl que esta distinción ya se ha tenido en cuenta en relación a los nombres distinguiendo lo que el nombre notifica (kundgibt) o las vivencias psíquicas, y lo que el nombre significa (bedeutet) o aquello a lo que se refiere el contenido de la expresión nominal añadiendo a esta una tercera diferencia consistente en lo que el nombre nombra (nennt) o el objeto de la representación. Estas distinciones, cree Husserl, son necesarias y para sostenerlas debemos establecer la diferencia entre el signo que es una expresión (Ausdruck) y el signo que es una señal (Anzeiche). El signo (Zeichen) siempre significa, esto es, el signo siempre es signo de algo (für etwas). "Pero no todo signo tiene una significación, un sentido que esté expresado en el signo". ${ }^{23}$ De entre los signos, los únicos que tienen significación son las expresiones. De modo que la distinción entre significar y significación se nos presenta como una distinción capital para comprender el concepto de significado en Husserl. Veremos que esta diferencia es la que justifica que este trabajo inicial sobre las significaciones deba situarse en el contexto del estudio de la lógica pura.

El tipo de conocimiento propio de la señal, esto es, el mostrar (Hinweisen mientras que el demostrar Beweisen es el conocimiento que corresponde a la lógica) al indicar mediante la existencia de un objeto la de otro, no deja de ser un conocimiento empírico. Lo que sucede es que, en sentido comunicativo, las expresiones también funcionan como señales realizando pues una función notificativa (kundgebende Funktion). Esto sucede en la medida en que, en el discurso comunicativo, el que habla emite para el que escucha expresiones que son señales de sus pensamientos, es decir, señales de sus vivencias psíquicas. En este sentido, la comprensión de esta notificación sígnica de la expresión no es un juzgar que cuente como un enunciar sino que, "consiste tan solo en que el oyente aprehende (apercibe) o simplemente percibe al que habla y lo percibe intuitivamente como una persona que expresa esto o aquello". ${ }^{4}$ De modo que lo que capta el oyente es la intención significativa del hablante al percibir la exteriorización de ciertas vivencias psíquicas. Esta percepción externa no es sino una presunta aprehensión que se lleva a cabo sobre la base de una representación intuitiva inadecuada, lejos por tanto de la percepción adecuada correspondiente a la verdadera aprehensión. Por cierto que en el lenguaje privado, en el monólogo o vida solitaria del alma (im einsamen Seelenleben) donde un sujeto se representa a sí mismo como comunicándose algo, por no ser esto una verdadera comunicación, no se da esta función notificativa y, sin embargo, las expresiones no dejan de serlo. Esto es lo que explica que la significación no se reduzca a la comunicación o función notificativa y, por consiguiente, que esta función no pertenezca a la esencia de lo que es una expresión.

Y es que la palabra no lo es sólo por su función notificativa, por su capacidad para estar dirigida a otra persona en el sentido antes visto, sino por su capacidad significativa, "que no puede coincidir con su función notificativa". ${ }^{25}$ Por eso la lógica no se agota en el análisis puramente verbal de las expresiones o de las palabras.

22 Cfr. Husserl, E. Logische Untersuchungen. The Hague, Netherlands: Martinus Nijhoff, 1984. En adelante, H $\mathrm{XIX} / 1$, p. $30 \mathrm{ss}$

$23 \quad I L$, p. 233

$24 \quad I L, \mathrm{p} .240$

$25 \quad I L$, p. 241 
Porque este revestimiento sígnico no es más que la apariencia contingente de la cosa misma que es la significación a la que el lógico debe llegar. Quedarse más acá sería capitular ante el aspecto sensible, reducir el problema del lenguaje al estudio de la gramática. ${ }^{26} \mathrm{Y}$ esta curiosamente es una tarea primera y primordial para la fenomenología que está en ciernes: distinguir, aunque sea a partir de complejas maniobras de diferenciación, el análisis gramatical del análisis fenomenológico de la significación que más tarde denominará gramática pura y que tendrá que ocuparse de las leyes a priori de composición y conexión de las significaciones en cuanto insertas en un juicio. ${ }^{27}$

Así pues, en esta función significativa de la expresión, podemos distinguir tanto el fenómeno físico o sensible-verbal, como los actos que le dan significación, actos que le confieren sentido a la expresión. Estos actos pueden ser de dos tipos: las intenciones significativas o los actos de dar sentido, que son esenciales para que toda expresión tenga significado, y los actos de cumplimiento o actos que otorgan la plenitud intuitiva (anschauliche Fülle) cuando la expresión se refiere o bien a algo objetivo que está presente actualmente, o bien a intuiciones concomitantes o, incluso, a algo representado en actos como el de la fantasía. Así pues, las intenciones significativas, esenciales para que la expresión sea algo más que una simple vox, pueden resultar plenificadas por otros actos, esta vez no esenciales, ${ }^{28}$ por medio de los cuales la expresión mienta (meint) algo (intención significativa) y al mentarlo se refiere a algo objetivo de alguna manera presente (acto de cumplimiento). La intención significativa es adecuada o realizada cuando está completada por estas intuiciones. De otra manera, la intención significativa resulta irrealizada o inadecuada cuando permanece clausurada en la propia intención significativa sin, por tanto, el nivel de trascendencia semántica que lleva al cumplimiento de esa intención. Es la intención significativa la que distingue el mero sonido verbal (foné) de la expresión $(\log 0 \mathrm{~s}){ }^{29}$

Al hablar efectuamos continuamente un acto de significación interior que se fusiona con las palabras y en cierto modo las anima. El resultado de esta animación es que las

26 El signo en Husserl nada tiene que ver con la significación y no cabe ninguna discusión sobre su correspondencia (Richtigkeit). En ningún caso el pensar y su fijación significativa (Zeihenhaft) se pertenecen recíprocamente. Es la tesis de uno de los estudios más clásicos de la filosofía del lenguaje de Husserl: Castilla Lázaro, R. Zur Husserls Sprachphilosophie und ihren Kritikern. Berlin: Diss, 1967, p. 69.

27 "El problema de una ciencia de las significaciones sería pues investigar la estructura legal esencial de las significaciones y las leyes en ella fundadas del enlace de las significaciones y de la modificación de las significaciones y reducir dichas leyes al mínimo número de leyes elementales independientes". Husserl, $I L$, III, p. 460. Por cierto que, en esta Investigación, aclara que deberá hablarse de gramática lógica pura para no confundirse con ninguna gramática general que contenga como especialidades accidentales todas las gramáticas particulares. Ibid, p. 468.

28 Que los actos de cumplimiento sean no esenciales al significado de una expresión es lo que explica que las expresiones sin objeto o incluso expresiones contradictorias, no carezcan, sin embargo, de significación. $I L \S$ 15. A partir de aquí, Alejandro Rossi cree que la única condición para que una expresión sea significativa es que sea comprensible. "Si comprendemos una significación es signo inequívoco de que posee significación y solo después sabremos si es verdadera o falsa". Rossi, A. "Sentido y sinsentido en las Investigaciones Lógicas" Dianoia, 6, 1960, pp. 91-114. De la cita, p. 114.

$29 \quad I L$, p. 245. De hecho el concepto de expresión implica el tener una significación y esto es lo que lo distingue de los demás signos. Una expresión que no tenga significación no lo es tal y no sería más que un conjunto de sonidos articulados que suenan a palabras. Cfr. $I L$, p. 254. Más adelante explica, "el significar es un carácter de acto, carácter teñido de tal o cual matiz y que supone un acto de representación intuitiva como su necesario fundamento. En el último se constituye la expresión como objeto físico. Pero esta se convierte en expresión -en sentido pleno y propio- merced al acto fundado". p. 269. 
palabras y la locución entera incorporan, en cierto modo, un significado, e, incorporado, lo comportan como sentido. ${ }^{30}$

Ahora bien, todas estas distinciones fenomenológicas, fenómeno de la expresión, intención significativa y eventualmente cumplimiento significativo, constituyen eine innig verschmolzene Einheit von eigenthümlichem Character, ${ }^{31}$ una unidad de la expresión en la que también insiste en Lógica Formal y Trascendental. ${ }^{32}$ Por tanto, cuando el fenómeno verbal físico toma el valor de una expresión es porque ha experimentado el cambio que supone la intención significativa (Bedeutungsintention) que constituye el acto de significar. Podría definirse la intención significativa como "una vivencia que se refiere (intención) a un objeto, siendo esta referencia (llamada después mención) lo que constituye el sentido o la significación de una expresión dada". ${ }^{33}$ La intención significativa ocuparía el espacio entre la audición de unos sonidos o la lectura de unas marcas sobre un papel, y la comprensión de estos actos como actos por los que se comprende algo. En realidad, podríamos pensar que ellos son la causa de que los signos verbales se refieran a cosas y de que las expresiones sean significativas.

En definitiva, explica Husserl, una expresión tiene significación cuando a su intención significativa corresponde un cumplimiento posible (mögliche Erfüllung). ${ }^{34}$ Este cumplimiento de la intención vacía es lo que en la esfera predicativa recibe el nombre de evidencia. Evidencia que se da cuando la intuición llena la proposición vacía, esto es, cuando la percepción es adecuada: cuando el objeto forma parte del acto, cuando lo percibido forma parte del acto de percepción. ${ }^{35}$ "El representante intuitivo es el objeto mismo tal como es en sí. Contenido representante y contenido representado son aquí una sola cosa idéntica" (repräsentierender und repräsentierter Inhalt sind hier identisch eines). ${ }^{36}$

La cuestión decisiva para el progreso de las Investigaciones consiste en saber si esta intención significativa se reduce al enlace entre las imágenes de la fantasía (Phantasiebildern) propias de los objetos mentados y el sonido verbal, o si estas

30 Husserl, E. Formale und transzendentale Logik. Versuch einer Kritik der logischen Vernunft. The Hague, Netherlands: Martinus Nijhoff, 1974. p. 27. En adelante, H XVII.

31 H XIX/1, p. 39. Más adelante denomina a esta fusión, unidad de cumplimiento (Erfüllungseinheit) 56.

32 Cfr. H XVII, § 3, p. 26.

33 A. Rossi, p. 95.

$34 \quad I L$, p. 255

35 Es muy interesante a este respecto la discusión sobre en qué medida se puede seguir sosteniendo la identificación entre adecuación y apodicticidad. Suponer tal cosa implica afirmar que solo el cogito es apodíctico y que la adecuación solo se da en lo que forma parte del cogito. "Dicho de otra manera; sólo hay apodicticidad cuando el ser se reduce al aparecer". Cfr. Fernández Beites, P. "La evidencia pre-predicativa. Apodicticidad como adecuación" en A. Serrano de Haro (ed.), La posibilidad de la fenomenología. Madrid: Ed. Universidad Complutense, 1997, pp.13-37. Ahora bien, el campo de lo apodíctico, gracias al descubrimiento de la intencionalidad del cogito, no es tan estrecho como podría parecer en el solipsismo aparente que presupone la reducción a la esfera de lo inmanente, ya que el mundo se recupera como objeto intencional. "Lo que nos enseña la intencionalidad es que lo que aparece es distinto del aparecer y, sin embargo, en tanto que correlato está apodícticamente dado en el cogito" Ibid, p. 22.

36 H XIX/1, p. 647. IL, p. 683. Antes había explicado que "Das Ideal der Fülle wäre demnach in einer Vorstellung erreich, die ihren Gegenstand, den vollen und ganzen, in ihrem phänomenologischen Inhalt beschlösse.” HUA $\mathrm{XIX} / 2$, p. 549. La evidencia ante-predicativa (y las significaciones pueden ser un tipo de estas) es la que funda la verdad de la predicación. "Si no le es lícito suponer nada como ya previamente dado, entonces ha de partir de algún conocimiento que no toma sin más de otro sitio, sino que, más bien, se da ella a sí misma, que ella misma pone como conocimiento primero". Husserl, E. La idea de la fenomenología. Madrid: FCE, 2004, p. 38 
imágenes pertenecen a los actos de cumplimiento de la expresión y por tanto a los elementos no esenciales. Evidentemente la segunda opción es la más adecuada. La comprensión de las expresiones persiste después de la desaparición de las representaciones o imágenes que la acompañan. Las imágenes son, pues, auxilios de la comprensión pero no elementos esenciales de la significación. ${ }^{37}$

Pues bien, entre el fenómeno de la expresión o el hecho de juzgar ${ }^{38}$ y las vivencias de dar sentido, tanto las intenciones significativas como los actos de cumplimiento, se da la diferencia entre el hecho psicológico consistente en el acto de notificar y que no pasa de ser una mera vivencia efímera (flüchtiges Erlebnis), y lo juzgado, el contenido que es siempre el mismo y que no puede reducirse al ámbito de lo subjetivo en el sentido de lo subjetivista y que Husserl llama contenido ideal (ideal Inhalt), esto es, la significación. A pesar de la pluralidad de personas y actos de significar, el significado no se ha degradado puesto que el juicio, en el sentido ideal, es uno. ${ }^{39}$ Esta especie o unidad ideal de significación es unidad en la pluralidad de las intenciones de significar. Y aquí regresamos a nuestro objetivo: este es el principio básico de lo ideal a cuya descripción está comprometida la fenomenología. ${ }^{40} \mathrm{Al}$ igual que a todas las unidades ideales, también a las significaciones les corresponden posibilidades reales. Así pues, las significaciones constituyen un grado de abstracción superior al de los individuos de la especie “acto de dar sentido". Cuando nos preguntamos por la idealidad del significado lo estamos haciendo por el significado in specie. Por ello, podrá decir que a cada expresión in specie (expresión pura que posee un índice de abstracción superior a cualquier fenómeno de la expresión, esto es, a cualquier caso particular de expresión empírica) le corresponde un significado in specie y viceversa. ${ }^{41}$

Y es esta idealidad la que, en definitiva, constituye la condición misma de la verdad. Las significaciones son precisamente unidades ideales ${ }^{42}$ que la fenomenología extrae al desprender de las expresiones los lazos psicológicos y gramaticales en los que se hallan entretejidas. Desprendimiento que recibe el nombre de Abstraktion y que no

37 Esto sucede cuando predomina el interés ingenuo objetivo que vive en los actos intencionales sin reflexionar sobre ellos. "Pero cuando el interés fenomenológico predomina, tropezamos con la dificultad de tener que describir relaciones fenomenológicas que sin duda hemos vivido innumerables veces, pero que normalmente no son conscientes; y tenemos que describirlas con expresiones que están acordadas a la esfera del interés normal, a las objetividades que se nos ofrecen en la percepción” $I L$, p. 246. Más adelante explica que, "la propensión natural a dirigir la vista hacia lo primariamente intuitivo y, por decirlo así, palpable de los fenómenos lógicos, seduce e incita a considerar los fenómenos interiores, que están junto a los nombres como las significaciones de los nombres". IL, p. 324.

38 El concepto de juicio que aquí se utiliza no debe confundirse con el juicio como significación de la proposición. Esto es lo que puede dar lugar a la confusión entre la unidad ideal aprehendida intelectivamente y el acto real de juzgar: "entre lo que el enunciado notifica y lo que dice". $I L$, p. 248.

39 Cfr. $I L, \S 31$. De hecho el título de esta sección es: "La significación es ideal y una".

40 "Rehabilitación del mundo ideal", es la expresión utilizada por Levinas, E. La teoría fenomenológica de la intuición. Salamanca: Sígueme, 2004. Advierte el filósofo francés que aunque las Investigaciones II, III y IV, contribuyen a la creencia generalizada de que la esencia de la fenomenología reside en su logicismo y platonismo, las Investigaciones V y VI, en las que Husserl accede a la conciencia para determinar la esencia de la representación de la verdad, hubiesen evitado aquel malentendido. Cfr. pp. 130ss

$41 \quad$ Cfr. $I L, \S 31$

42 Cfr. HUA XIX/1, § 29 Die reine Logik und die idealen Bedeutungen. Significaciones que, según explicará, son el género de todas las especies lógicas: conceptos, proposiciones, inferencias... que son universales y que contienen o pueden contener bajo ellas individuos. Esta concepción esencial de las significaciones fue puesta en cuarentena por el propio Husserl tanto en Formale und Trascendentale Logik $\S 57$ como en Erfahrung und Urteil. 
debe confundirse con el proceso psicológico que recibe el mismo nombre ni siquiera con la inducción empirista. Las significaciones constituyen una clase particular de especie semejante a las especies lógicas que mantienen con los actos de significar, lo veremos enseguida, la misma relación que la especie rojo con el rojo particular de las rayas rojas pintadas, siguiendo el mismo ejemplo de Husserl. Por ello reconoce que, siendo verdad que los excesos del realismo han sido la causa de la negación tanto de la realidad de los conceptos como de la objetividad de las especies, es preciso distinguir entre las singularidades individuales (individuellen Einzelheiten) como son las cosas empíricas, y las singularidades específicas (spezifischen Einzelheiten) ${ }^{43}$ como son los números, las multiplicidades de la matemática, las representaciones y los conceptos y proposiciones de la lógica pura. ${ }^{44}$ Cuando la fenomenología llega a una investigación tal, está accediendo im Bannkreise der reinen Logik. ${ }^{45} \mathrm{Y}$ esta esfera de la lógica pura es la que debe permitirnos comprender que las significaciones son unidades ideales que, a pesar de poder ser expresadas mediante diferentes expresiones pensadas en diferentes vivencias, no pueden ser confundidas ni con las expresiones accidentales ni con las vivencias también accidentales del que piensa. Por ello, que los actos subjetivos que dan significación a las expresiones (ya sean vacilantes, vagas, incompletas, anómalas u ocasionales) no debe confundirse con el hecho de que las significaciones mismas puedan cambiar.

La investigación fenomenológica requiere seguir insistiendo en la diferencia entre la idealidad, pureza o validez objetiva de la significación (Bedeutung) y la posible contingencia del significar (Bedeuten) ${ }^{46} \mathrm{El}$ ámbito subjetivo, puramente psicológico-descriptivo, y el ámbito objetivo-ideal sólo se presentan como aspectos separados a una mirada fenomenológica. Como las significaciones son idealidades, no pueden ser causa ni efecto ni pueden ejercer ningún tipo de influencia sobre los seres reales al no estar inmersas en el tiempo. Mientras que las significaciones son especies, los actos de juzgar son temporales, resultan determinados causalmente y son reales en el preciso sentido de no ser ideales. ¿Cómo se relaciona entonces lo contingente del decir con lo ideal del contenido de ese decir? ¿Cuál es la relación que se da entre el significar relativo consecuente del acto de juzgar y las significaciones como especies? Probablemente en Investigaciones Lógicas, para forzar todavía más los argumentos en contra del psicologismo, se acentúa la diferencia entre las leyes lógicas y las leyes psicológicas en cuanto leyes naturales como si a las primeras les estuviera vedada la posibilidad de influir en nuestro pensamiento. En cualquier caso, desde dentro de $I L$ no es posible salvar el abismo de la diferencia categorial entre la idealidad de las significaciones y la temporalidad de las vivencias. ${ }^{47}$

43 Y a esta distinción le corresponde la diferencia entre universalidades individuales y universalidades especificas.

44 Cfr. IL p. 299. "Die idealen Gegenstände hingegen existieren wahrhaft" Hua XIX/2, 124. De modo que el ser de lo ideal no solo se refiere a lo en la conciencia sino también a lo que está fuera de la conciencia. Real es pues, para la fenomenología, tanto lo inmanente como lo trascendente.

45 HUA XIX/1, p. 92. Puede verse a este respecto el clásico trabajo de Bar-Hillel. "Husserl's conception of a purely grammar". Philosophy and Phenomenological Research, 17, 1957, pp. 362-369.

46 HUA XIX/1, p. 95. Derrida propone que se traduzca Bedeuten como querer-decir (volouir-dire) mientras que Bedeutung sería siempre eso que alguien o un discurso quieren decir. Cfr. Derrida, J. La voix et le phénomène. Introduction au problème du singe dans la phénoménologie de Husserl. Paris: Quadrige/PUF, 1998. p. 18

47 Podría pensarse que una manera adecuada de reducir esta diferencia y explicar la relación podría ser la intencionalidad constitutiva de las vivencias, pero ello dejaría sin aclarar de qué manera los objetos intencionales determinan las vivencias correspondientes. A este respecto García Norro propone que esta relación pueda ser regulada desde la causa formal. "Nos preguntamos si no habrá sido el borroso atisbo de la necesidad de una 
El objeto a que se refiere la expresión y la significación misma no coinciden nunca, aunque es evidente que entre ambos existe una estrecha conexión: no hay otra manera por la que la expresión se refiera a un objeto que no sea por la significación. Esta diferencia entre el contenido de la expresión y el objeto al que se refiere la expresión puede comprobarse en el hecho de que "varias expresiones pueden tener la misma significación pero distintos objetos o el mismo objeto pero distintas significaciones". ${ }^{48}$ Esta es la diferencia resultante de distinguir en una expresión no sólo lo que dice sino también acerca de qué lo dice. Si no diferenciáramos vivencia y objeto no podríamos hacer frente al fenomenismo. Ahora bien, esta diferencia no es óbice, más bien al contrario, para explicar la referencia objetiva de la expresión y que Husserl define así: "la expresión designa su objeto mediante su significación $\mathrm{y}$, respectivamente, el acto de significar es el modo determinado de mentar el objeto en cuestión." 49

Atendamos aunque sea brevemente al concepto de mención para comprobar cómo se está aproximando ya al tema fundamental de la Investigación Quinta: la consideración de la esencia de las vivencias en su referencia a un objeto u objetividad. Los actos de dar sentido son, lo sabemos ya, vivencias intencionales. Vivencias que son entendidas como los acontecimientos reales que aunque cambiantes de momento a momento y fusionados unos con otros constituyen die reale Bewusstseinseinheit, la unidad real de la conciencia de cada individuo psíquico. ${ }^{50}$ Pues bien, la intencionalidad se constituye precisamente en la mención de algo. Algo que (obsérvese el giro respecto del quasi platonismo de las investigaciones previas) pudiendo existir en la conciencia no tiene por qué existir en la realidad. Y así, lo que el programa de la fenomenología trascendental va a suponer respecto del esencialismo eidético previo y lo que añadirá respecto al cartesianismo asumido y superado, es el reconocimiento del cogitatum como constitutivamente correlativo al cogito. "El objeto es mentado, es decir, el mentarlo es vivencia; pero es meramente mentado y en verdad no es nada". ${ }^{51}$ Por eso la mención es la vivencia intencional o acto de dar sentido (intención significativa) que constituye la significación de una expresión independientemente de que esa intención resulte cumplida o no. Mientras que el cumplimiento es un acto de dar sentido esencial para el análisis de la función cognoscitiva de la expresión, es independiente para el análisis de la significación, lo hemos explicado ya. ${ }^{52}$

Husserl intenta discutir la idea por la cual se entiende que la significación de una expresión depende de la coordinación de los sonidos verbales con las imágenes de la fantasía, de modo que, sin ellas, estaríamos ante una expresión sin sentido. Y es que ello supondría desconocer que lo que distingue la palabra como complejo sensible de la palabra como expresión significativa es la intención significativa que puede no

\footnotetext{
relación de este tipo la que llevó a Husserl a sostener que las significaciones se individualizaban, constituían momentos no independientes, formas, en una palabra, de las vivencias correspondientes". García Norro, J. J. "La respuesta husserliana en las Investigaciones Lógicas a la aporía del antropologismo." Logos. Anales del seminario de metafisica, 27, 1993, pp. 127-135. De la cita, p. 135.

50 Hua XIX/2, 326

$51 \quad I L, \mathrm{~V}$, p. 494. En la Introducción a esta Investigación aclara que lo significativo de cada acto particular de dotar de significado reside en el carácter de acto (Aktcharakter) y no en el objeto, y reside en lo que hace de ella una vivencia intencional referida a objetos. En Ideas Husserl hace corresponder con el sentido o esencia del acto un determinado modo de darse el objeto. El sentido pasa a ser el objeto en el cómo de su modo de darse.
}

$48 \quad I L$, p. 249

$49 \quad I L$, p. 250

52 Cfr. $I L$, p. 248 
ser completa y adecuada por medio de imágenes concomitantes. Para los empiristas, la mención reside en las representaciones intuitivas individuales confundiendo la significación de una expresión con el objeto al que se refiere la representación y por tanto no haciendo la distinción entre los actos de dar sentido esenciales como son las intenciones significativas y los no esenciales o actos de cumplimiento. Carece pues de sentido para ellos -explica Husserl en el juicio al nominalismo- distinguir entre intuiciones individuales y representaciones universales. Olvidan los nominalistas que los objetos no están en la conciencia sino que se constituyen en diferentes formas de intención objetiva como lo que son y valen para nosotros. ${ }^{53}$ Adviértase aquí la importancia de lo que luego va a significar el viraje trascendental de la fenomenología precisamente determinado por la constitución de toda objetividad en la subjetividad pura.

En definitiva, el significado de una expresión, según Husserl, depende de la significación, esto es, de la mención de una proposición a la que se llega mediante el acto significativo o acto de dar sentido. Para llegar aquí, ha sido preciso establecer una serie de presupuestos y de sutiles distinciones fenomenológicas cuyo fundamento es que la significación se refiere al ámbito de lo ideal, a las cosas mismas, al ámbito de la objetividad no sujeta a la temporalidad del significar, de las vivencias concretas de dar sentido. Es preciso diferenciar, pues, lo que la expresión notifica, esto es, lo que podemos llamar la función semántico-comunicativa de la expresión basada en la relación entre el hablante y el oyente a partir del reconocimiento de sus peculiares intenciones significativas, de lo que la expresión significa, la significación que pertenece ya al ámbito de lo ideal. Pero además, no puede confundirse la significación con el objeto al que se refiere la mención. Ya sabemos que ese objeto, según se aclara en la Investigación $V$, es intencional y, como cogitatum, existe en la conciencia como correlato de una vivencia. Ese existir inmanente ${ }^{54}$ es apodíctico (todavía no hemos llegado al método de la reducción, pero aquí están puestos los rudimentos) y para nada prejuzga algo sobre su índice de existencia que ya, para la fenomenología naciente, es un dato neutralizado. ${ }^{55}$ Significación y referencia no pueden identificarse aunque, como es evidente, toda referencia es posible gracias a la significación. De este modo, el contenido de lo que una expresión expresa es el contenido intencional o materia del acto, en definitiva, lo que una proposición verdaderamente dice.

\section{Tesis sobre la idealidad en el Husserl de la fenomenología eidética}

La filosofía del s. XX empezará, según Serrano de Haro, por este atrevimiento de reconocer algo parecido a "objetividades puras" que se sitúan fuera del tiempo, que son ajenas al cambio, que carecen de materia física sin ser tampoco meros contenidos de conciencia. ${ }^{56}$ Lo que sucede es que este proyecto realista fue abandonado enseguida.

\footnotetext{
$53 \quad I L$, p. 338

54 Husserl diferencia entre la inmanencia ingrediente propia de los actos o noesis y la inmanencia no ingrediente de los objetos intencionales.

55 "a todo lo trascendente (a todo lo que no me es dado inmanentemente) hay que adjudicarle el índice cero; es decir, su existencia, su validez no deben ser puestas como tales" Husserl, La idea de la fenomenología, p. 96

56 Serrano de Haro, A. Paseo filosófico en Madrid. Madrid: Trotta, 2016, p. 52. Según Serrano de Haro, "no está claro si esa fenomenología en vanguardia se limita a invitar al reconocimiento de este orden abstracto de seres, o si más bien ella hace del mundo de las ideas su ámbito científico privativo exclusivo; una cosa es admitir la
} 
De las $I L$, tan solo la I Investigación se mantiene en esta rehabilitación de lo ideal al estilo platónico. En nuestra opinión, y de acuerdo con las investigaciones más contemporáneas sobre Husserl, es pertinente una profundización en esta incipiente fenomenología si en ella, aun reconociendo el fracaso y el abandono posterior de un realismo eidético tan exagerado como ingenuo, se pueden descubrir los puntales de la fenomenología que permanecen en toda la obra de Husserl a pesar de que en las distintas etapas de su pensamiento tales cuestiones decisivas resulten abordadas de formas distintas. De esta manera, se advierte que hemos comprendido estas tesis que vamos a exponer ahora no sólo ciñéndonos a los primeros trabajos de Husserl sino fundamentalmente a las obras centrales de la etapa de Gotinga: Ideas y La filosofía como ciencia estricta.

Si la fenomenología trascendental es consecuencia del proceso de maduración interno de la fenomenología eidética, puede entenderse que tanto la intencionalidad y sobre todo la epojé y la reducción continúan, de alguna manera, el mismo objetivo de hacer de la fenomenología una filosofía primera ahora ya sin el compromiso del realismo. Analicemos, pues, qué aspectos de ese primer realismo eidético pueden considerarse tesis para la fenomenología. ${ }^{57}$

i. Lo ideal tiene que ver epistemológicamente con la cuestión de la validez. La existencia de objetos ideales le muestra a Husserl un reino de objetos con una validez independiente de los actos psíquicos por el que llegan a comprenderse, como si su desvinculación del psicologismo fuera parejo a la aceptación de un cierto platonismo. De hecho, sostiene Husserl, la verdad o validez objetiva de las leyes de la lógica es eterna o, mejor, es una idea y como tal es supratemporal, se piense en ella o no. ${ }^{58}$ La propuesta de la fenomenología es que la idealidad ${ }^{59}$ viene dada por su carácter puro, esto es, por el hecho de que las significaciones o los números no pueden reducirse a las vivencias contingentes del enumerar o del significar. ${ }^{60}$ ¿Pero de qué significaciones estamos hablando? ¿Tiene el mismo grado de idealidad la significación de un objeto particular cuyo eidos lo hace pender de un género que la significación correspondiente a un principio lógico? En mi opinión esta ambigüedad, que no resulta demasiado aclarada en la I Investigación y que se mantiene todavía en la Introducción a la VI Investigación cuando Husserl reconoce que no se ha logrado poner en claro el origen de la idea de significación, ${ }^{61}$ puede plantearse

autonomía epistemológica de tales objetividades, otra muy distinta reclamar como el campo del propio saber esas ideas al modo platónico.” p. 54.

57 García-Baró ha explicado ya algunas características de la idealidad. Algunas de estas son: Las unidades ideales son todas especies; Las significaciones, los objetos lógicos, son todos unidades ideales y al ser especies penden de ella individuos; Los individuos del género significación están en la conciencia y son ciertas partes del acto de significar o de dar sentido; Por último, hay objetos reales y objetos ideales cuyo criterio de demarcación es el tiempo. García-Baró, M. "La filosofía primera de E. Husserl en torno a 1900” Dianoia, 32, 1986, pp. 41-69. De la cita, pp. $41 \mathrm{ss}$

$58 \quad I L$, p. 131

59 Idealidad de las significaciones que es "un caso particular de la idealidad de lo específico en general". IL, p. 288

60 "El investigador científico sabe que él no hace la validez objetiva de los pensamientos y conexiones de pensamientos ni la de los conceptos y verdades, como si se tratase de accidentalidades suyas, sino que las ve con intelección, las descubre". IL, p. 283

${ }^{61}$ Cfr. $I L$, p. 598. A pesar de que la significación de las expresiones resida en la esencia intencional de los actos correspondientes, "todavía no ha sido considerada la cuestión de qué especies de actos son en general aptos para desempeñar la función significativa o de si en este respecto no se hallan más bien al mismo nivel los actos de toda especie". 
mejor acudiendo a Ideas ${ }^{62}$ En el primer libro de este trabajo y en el contexto de la determinación conspicua entre el ámbito de lo eidético y el de lo fáctico, Husserl observa distintos grados de idealidad dependiendo de que sea una esencia dotada de contenido material o una esencia vacía, esto es, lógico pura. Toda una escala eidética cuya máxima concreción corresponde a las singularidades eidéticas y cuya máxima generalidad está presidida por un sumo género. Cada una de las superiores hace las veces de especie respecto de las inferiores excepto en el caso de la inferior que, evidentemente, ya no es especie de ninguna, y en el caso de la superior, que ya no remite a otra más general por no tener sobre sí ningún género. Estamos pues, en el dominio de la lógica pura, y este es el lugar de las significaciones cuyo sumo género sería significación en general de la misma manera que el número cardinal es el sumo género de la matemática del que penden como singularidades eidéticas los números dos, tres etc... El propio Husserl aclara en este contexto y en nota al pie, cómo la morfología de las significaciones (tanto las formas sintácticas como las materias sintácticas) son parte fundamental de una gramática a priori como disciplina perteneciente al ámbito de la lógica pura. ${ }^{63}$

Así pues, en mi opinión, cada significación relativa a cada uno de los miembros de una proposición tendría el mismo grado de idealidad que los números, pues unos y otros son singularidades eidéticas que ya nos sitúan de lleno en el terreno de la lógica pura. Las significaciones singulares (así lo expresa en la IV Investigación) serían pues relativas a las categorías de significación o géneros esenciales pertenecientes $a$ priori a la esfera de las significaciones y siempre de un nivel de idealidad superior, si es que puede hablarse así. En cualquier caso y para lo que nos interesa, lo que se desprende de aquí es la lección husserliana de que la fundamentación de la lógica pura depende de la posibilidad de establecer una teoría del conocimiento en sentido idealista. Entendiendo por idealismo no una doctrina metafísica, sino la epistemología que reconoce lo ideal als Bedingung der Möglichkeit del conocimiento objetivo $^{64}$ determinando así la preeminencia del ordo idearum atemporal, inmutable y radicalmente independiente de actos productivos o intersubjetivos. Husserl se refiere a las objetividades ideales, sin que el concepto de objetividad tenga que ver algo con el concepto de realidad manejado por el empirismo exclusivamente apegado al ámbito de lo fáctico, de lo verificable por los sentidos. La experiencia que requiere la filosofía, explicará Husserl en las lecciones de 1923/24 sobre Erste Philosophie, debe poseer la radicalidad que no se observa en las cosas del mundo. La validez de lo ideal conforma, pues, el terreno donde el conocimiento no se hace resbaladizo por estar fundado sobre la estricta necesidad. Y es aquí donde lo ideal es descrito con una independencia tal de lo fáctico que la existencia empírica de lo cogitatum resulta fenomenológicamente irrelevante. Si se suspende la obligación de juzgar sobre la realidad o no de algo para quedarse sólo con lo manifestado a la conciencia, eso que esencialmente se le aparece, el eidos, en tanto que se da, es un dato apodíctico, indiscutible. "La crítica del conocimiento -explica Husserl- quiere más bien ilustrar, sacar a la luz la esencia del conocimiento y la pretensión de validez que pertenece a esta esencia; y esto, ¿qué otra cosa quiere decir, sino traerla a que se dé directamente ella misma?" 65

\footnotetext{
Ideas, § 12 .

A esto se ha dedicado en la $I V I L$.

Cfr. IL, p. 296

Husserl, La idea de la fenomenología, p. 41.
} 
ii. El acceso al ámbito de lo ideal descubre al fenomenólogo distintos grados de idealidad a la vez que le obliga a reconsiderar cuáles son los márgenes de lo real. Los números y las significaciones que, insistimos, en Ideas denominará singularidades eidéticas, son un modelo de lo que Husserl quiere decir con las cosas mismas, rescatando el concepto 'cosa' de los estrechez del empirismo mentor de las ciencias. Real, explica Husserl, es un predicado aplicable tanto a lo 'en la conciencia' o inmanente como a lo 'fuera de la conciencia' o trascendente. El criterio ontológico de la fenomenología para distinguir la realidad de la idealidad queda expuesto en el $\S 8$ de la II Investigación, y no es otro que el tiempo "Como nota característica de la realidad definiremos la temporalidad (...) Pues lo único que aquí importa es la oposición al 'ser' intemporal de lo ideal". ${ }^{66}$ Preguntémonos, pues, qué son estas objetividades ideales. ${ }^{67}$ Lo primero que hay que decir es que 'objeto' en Husserl es un concepto más amplio que el de realidad cuyo sentido estrecho está acotado al ámbito de las existencias individuales. Objeto, pues, puede llegar a referirse, en la exposición de los grados de idealidad, a algo cualquiera en general. De modo que el ámbito de la objetividad propio de las ciencias lógico-formales no se refiere a cosas reales, pero tampoco a simples productos de la imaginación sino a "entidades enteramente objetivas y aprehensibles con plena evidencia intelectual". ${ }^{68}$ Ahora bien, como existen distintos niveles de idealidad, si tomamos el ejemplo de las matemáticas, los eide de la geometría son un tipo de esencias distinto a los de las restantes disciplinas de la mathesis universalis. ${ }^{69}$ Por ejemplo, las esencias de la geometría euclidiana tienen un contenido esencial material porque son objetividades ideales del espacio puro, mientras que los objetos ideales de la mathesis universalis son vacíos de contenido o meramente formales. Los objetos ideales eidéticos materiales fundan las ontologías eidéticas u ontologías regionales donde las ciencias de hechos encuentran sus fundamentos teóricos; los objetos ideales eidéticos formales, por su parte, exigen un nivel de racionalización o abstracción más elevado al referirse a una esencia completamente vacía "que se ajusta a todas las esencias posibles". ${ }^{70}$ Estas esencias fundan las ontologías formales que en su seno albergan todas las ontologías regionales posibles en general. De modo que Husserl distingue ya entre las objetividades reales o individuales, los eide materiales como los de la geometría, y el estrato superior de las entidades formales. Y este, cree Husserl, ha sido el error de los matemáticos y de los lógicos, no haber sido capaz de distinguir estos modos distintos de las objetividades ideales. ${ }^{71}$ En Husserl, pues, observamos ya la distancia

66 Husserl, IL, II, § 8, p. 308

67 Seguimos aquí el trabajo de Rizo-Patrón, R. “Objetividades matemáticas, ¿̇reales o ideales? Reflexiones desde el pensamiento de E. Husserl”, en Areté. Revista de Filosofia, vol. XXIV, 2012,1, pp. 181-201. Escribe Husserl: "La matemática no se ocupa de espacios reales, cuerpos reales, superficies reales etc... como los de la realidad fáctica de la naturaleza sino que se ocupa de espacios, de cuerpos, de superficies representables en general y por ello pensables de modo coherente" Husserl, E. Renovación del hombre y de la cultura. Madrid: Anthropos, 2012, p. 14

${ }_{68}$ Husserl, E. Ideas relativas a una fenomenología pura y una filosofía fenomenológica. Madrid: FCE, 1993, p. 60

69 Cfr. Ideas, pp. 30ss

70 Husserl, Ideas, p. 33. "Se me ocurrió que la evidencia de las verdades matemáticas formales era enteramente distinta a la de las otras verdades a priori; es decir, que aquellas no necesitaban de ninguna intuición ejemplar concreta de algún objeto o situación objetiva, aunque se refirieran a ella con generalidad formal vacía." Lógica formal, p. 15

71 "Es tiempo ya de rechazar al fin los viejos prejuicios y de ponerse a la gran tarea, máximamente necesaria, de fundamentación de todas las ciencias aprióricas, para así dar a la vez cumplimiento a la plena y auténtica idea de una mathesis universalis que rebasa con mucho la idea leibniziana” Husserl, Renovación, p. 19 
entre el orden de las cosas y el de las ideas sin que pueda hablarse del horismós platonico.

iii. Lo ideal sólo puede ser captado por una intuición eidética. ${ }^{72}$ Para llevar a cabo la intuición eidética es preciso proceder a un tipo de Abstraktion o ideación que luego denominará reducción. Es decir, debe aceptarse con plena vigencia sólo el eidos del objeto que se consigue eliminando las particularidades no esenciales del mismo. Cuando se descubre que todo objeto es algo más que su componente fáctico, se entiende cómo ese objeto, además de darnos lo que nos da en un momento, abre un horizonte propio de posibilidades de manifestación, un horizonte de sentido que no se agota en su mero acontecer fáctico. Ahora no es suficiente con una generalización inductiva como la que lleva a las ciencias empíricas al descubrimiento de los eide morfológicos, sino una abstracción eidética ${ }^{73}$ que nos permita acceder a estas "ideas en el sentido kantiano"74 cuyo modo de ser es ideal y exacto. De este modo, los objetos ideales que se descubren por variaciones imaginativas, representan el ámbito de lo invariante, del mínimo no poder ser de otra manera..$^{75}$ Variaciones imaginativas que nos permiten llegar a la esencia que en Erfahrung und Urteil queda definida como aquello sin lo que el objeto no puede ser pensado. Pues bien, el darse de las cosas mismas, la fenomenicidad del fenómeno, es lo captado por la intuición entendida como principio de todos los principios ${ }^{76}$ y ahí es donde se da la evidencia que sustenta la verdad, el ideal buscado de la fenomenología. Una evidencia que equivale a presencia, esto es, al estar de las cosas mismas - del eidos-presente ante la conciencia con una necesidad nunca dable por lo fáctico. De modo que la verdad intuitiva o ante-predicativa (Anschauungswahrheit) es más fundante y originaria que la verdad proposicional (Satzwahrheit). Es la distancia entre la verdad de lo ideal (tenga el grado de universalidad que tenga) y la verdad correspondiente a las vivencias como individuos concretos de esas especies, ya sean los actos de enumerar o los actos de significar.

72 Que no se nos da mediante una intuición empírica: "Para que el mundo natural, real, que nos rodea esté ahí delante para nosotros y sea percibido basta con abrir los ojos y estar despiertos. No ocurre lo mismo con los mundos circundantes ideales como el mundo aritmético". Ideas, p. 68. en la Introducción a este primer tomo de Ideas aclara Husserl: "del paso a la pura esencia resulta por una parte el conocimiento esencial de algo real (el conocimiento del factum según su qué) y, por otra, un conocimiento de algo irreal (esto es, el conocimiento mismo de ese qué, de la esencia)".

73 La abstracción ideativa es un proceso que se acerca más a la imaginación que a la percepción sensible ya que esta última es más pasiva y receptiva y, por tanto, menos espontánea. La abstracción eidética produce siempre eide, conceptos, significaciones que son siempre generales mientras que la imaginación produce imágenes particulares. Además, la imaginación tiene un peso decisivo en la captación de los eide formales mediante la intuición eidética del universal al que se llega mediante las variaciones imaginativas. "El ser individual de toda índole es "contingente" (...) Pero en el sentido de esta contingencia se encierra el estar correlativamente referida a una necesidad (...) una necesidad esencial que, por ende, se refiere a una universalidad esencial" Husserl, Ideas, $\S 2$, p. 19.

74 Husserl, Ideas, pp. 165-166

75 Escribe Husserl, "Los conceptos fundamentales que el matemático engendra originariamente en intuición general son generalidades puras, intuidas directamente desde las individualidades fantaseadas; sobre la libre variación de estas individualidades, las generalidades se destacan como el sentido general idéntico que las atraviesa y que en ellas se individualiza (...) Con conceptos obtenidos originariamente de este modo opera la matemática; ella engendra las leyes de esencia inmediata -los llamados axiomas- que corresponden a tales conceptos como verdades necesarias y generales en sentido estricto que no admiten la posibilidad de excepción ninguna en absoluto (Kant)" Husserl, Renovación, p. 15

76 Husserl, Ideas, p. 58 
iv. Lo ideal funda el carácter estricto de la cientificidad filosófica que se busca, por eso el paso más grande que tiene que dar nuestra época es reconocer la existencia de este ámbito que funda un conocimiento riguroso. ${ }^{77} \mathrm{La}$ filosofía consiste precisamente en la experiencia fenomenológica, esto es, en ser ciencia estricta de la esencia. Y así, serán las significaciones y los números (de nivel de idealidad que sea) las que constituyan algunos de los objetos de la gramática pura o de la matemática pura. La fenomenología representa el secreto anhelo del racionalismo en la medida que se propone ser ciencia estricta. Es evidenciación intuitiva fundada en la apelación objetiva a la intuición en la que encuentra nuestro saber su última y estricta verdad absoluta. ${ }^{78}$ Este intento de hacer de la filosofía una ciencia estricta le coloca ante dos frentes: el del psicologismo y el del historicismo precisamente dos teorías que tratan de fundar la validez absoluta en algo que no la tiene: en los hechos. En La filosofía como ciencia estricta, Husserl denuncia que el psicologismo y el historicismo son teorías reduccionistas que, al mundanizar las ideas, las desvinculan de todo valor y de toda norma. La fenomenología, en consonancia con el ideal griego y renacentista, quiere presentarse como la expresión de este saber radical y universal, omniabarcante y global que históricamente ha poseído la filosofía ${ }^{79}$ entendida ahora como allbefassende Wissenschaft. Sólo una lógica trascendental advierte Husserl- permitirá comprender que las ciencias positivas están fundadas en una racionalidad relativa, unilateral "que deja presente su necesario reverso: una plena irracionalidad". 80

v. Lo ideal no se agota en los actos concretos o procesos de ideación. Lo sustancial de $I L$ es la descripción de los actos en que vivimos la verdad partiendo de una ontología formal more brentaniana que se presenta ahora como filosofía primera. El decir y el enumerar son solo realizaciones concretas que encuentran su sentido en la esfera de lo ideal sin que esta se reduzca a aquellos, o alguna vez aquellos agoten la inmensidad de este. Los eide no son el resultado de un proceso productivo. En el $\S$ 35 de la I Investigación aclara que lo ideal define un conjunto de objetos genéricos a los que no les es esencial el ser pensados y expresados..$^{81}$ Esta es una caracterización

77 "El paso más grande que tiene que dar nuestra época es reconocer que con la intuición filosófica en su genuino sentido, con la captación fenomenológica de la esencia, se abre un campo infinito de trabajo y una ciencia que (...) adquiere, sin embargo, una cantidad de conocimientos, de los más rigurosos y decisivos para toda la filosofía anterior" Husserl, E. La filosofia como ciencia estricta. La Plata: Terramar, 2007, p. 67. La inflexión entre filosofía y matemática va a ser, según Carlos Díaz, lo que constituya la cuestión de la ciencia rigurosa. Y justamente el problema de la significación es el que resume con más nitidez tal fusión. Cfr. Díaz, C. "La teoría de la significación en Husserl”. Logos. Anales del seminario de metafísica, 4, 1969, pp. 41-58.

78 Cfr. Zubiri, X. Cinco lecciones de filosofia. Madrid: Sociedad de Estudios y Publicaciones, 1963, p. 243. Zubiri explica que, al problema del origen y planteamiento del problema filosófico como término de una ciencia absoluta respondió Husserl con el concepto de reducción. Mientras tanto, al problema de la posibilidad de la filosofía como ciencia estricta, la fenomenología responde con el concepto de intuición. Por último, al problema de la cuestión radical de la filosofía, Husserl se acerca con el concepto de constitución.

79 La función de la filosofía consistirá en recordar al hombre su vinculación con la totalidad del ser, "ihr die Form des bewussten Bindung zu verleihen, einer Bindung, in der Seine spezifische Würde und Seine Freiheit verwurzelt ist." Landgrebe, L. "Zur Überwindung des europäischen Nihilismus. Der Nihilismus als Phänomen des Geistesgeschichte in der wissenschaftlichen Diskussion unseres Jahrhunderts”, en Arendt, D., Der Nihilismus als Phänomen der Geistesgeschichte in der wissenschaftlichen Diskussion unseres Jahrhunderts. Darmstadt: Wissenschaftliche Buchgesellschaft, 1974, p. 36.

80 Husserl, Lógica formal, 21

81 Y según Derrida, les es esencial también el poder ser repetidas. La idealidad absoluta, explica, es el correlato de una posibilidad de repetición indefinida. Derrida, p. 58. 
de lo ideal que viene otra vez forzada, a mi modo de ver, por el interés de Husserl en distinguir la idealidad de la fenomenología, de la universalidad del psicologismo en cuanto resultado de un acto productivo. Acaso la pregunta fundamental de la fenomenología sea acerca de cómo es posible describir unidades de validez absoluta por medio de actos subjetivos puntuales. "Hay incontables significaciones que en sentido corriente relativo de la palabra son significaciones meramente posibles, no llegando nunca a expresión e incluso no pudiendo llegar nunca a expresión, a causa de las limitaciones de las fuerzas cognoscitivas en el hombre". ${ }^{82} \mathrm{Y}$ esta, que es la clave de la relación entre lo ideal y lo particular contingente, explica también la posibilidad del progreso en la formación de nuevos conceptos. Lo ideal determina una esfera del ser pre-existente y por eso es posible realizar nuevas formaciones conceptuales de significaciones que siempre son más amplias e inabarcables que los actos de significar o que la permanente producción conceptual donde lo ideal entra en el campo de lo real. Lo ideal abre la fenomenología a la descripción del dominio de lo a priori que se extiende por las distintas regiones y que se descubren por medio de la reducción eidética o puesta entre paréntesis de la posición de existencia de los particulares que caen bajo cada eidos, bajo cada invariante que se mantiene en la variación.

\section{Conclusión}

El problema del conocimiento que pone sobre la mesa la fenomenología es cómo lo trascendente puede, de alguna manera, ser inmanente, teniendo en cuenta que lo inmanente delimita el ámbito de lo dado evidentemente, de lo dado en la intuición. El proyecto de la fenomenología consiste en derribar la frontera entre lo inmanente y lo trascendente como si de ámbitos ontológicos opuestos se tratara. ${ }^{83} \mathrm{La}$ evidencia de lo dado no sólo se referirá, en la fenomenología trascendental posterior, al acto noético de la vivencia sino al propio contenido intencional noemático, contenido que posee una inmanencia trascendente ${ }^{84}$ que no implica salir de la conciencia trascendental y, por tanto, aseverar nada acerca de la realidad fáctica del noema u objeto intencional ${ }^{85}$ (cuyo descubrimiento, por cierto, es consecuencia del fracaso del proyecto realista de Husserl). La subjetividad descubierta por la reducción -explica San Martín- no es sino la "indisoluble unidad" de tener experiencia de mundo y el mundo dado en esa experiencia. ${ }^{86}$

$82 \quad I L$, p. 291

83 Proyecto que fundamentalmente toma cuerpo en la fenomenología trascendental que lo lleva a reformular conceptos como el de la subjetividad y el de la objetividad de las $I L$. La concepción de la subjetividad abandona el ámbito de la inmanencia real para presentarse como un principio unitario del flujo de la conciencia. Por su parte, la objetividad como ámbito de lo totalmente trascendente, en el sentido de independiente, evoluciona para entrar en contacto con la nueva estructura de la subjetividad. Cfr. Rizo-Patrón, 2002. p. 243

84 Los conceptos de inmanencia ingrediente y de inmanencia trascendente aparecen bien definidos en la tercera conferencia de La idea de la fenomenología, para diferenciar así la sutil diferencia entre la inmanencia del acto noético y la inmanencia del contenido noemático, siempre vinculado y correlacionado con su acto correspondiente con el que forma la indisoluble unidad de la vivencia que, evidentemente, es ya siempre inmanente por constituir precisamente lo que sea la conciencia.

85 El objeto intencional es el objeto al que se llega mediante la epojé que nos permite abandonar la realidad física del mundo del que como totalidad no podemos tener experiencia (pues sólo se nos da en escorzos) para identificarlo con el mundo en cuanto que es dado o en cuanto puede ser dado.

86 Cfr. San Martín, J. "La despedida de Husserl del cartesianismo según Landgrebe.” Ágora. Papeles de Filosofí, 
El fracaso del proyecto realista de $I L$, que no el fin de discurso sobre la idealidad, tiene que ver con la propia maduración de la fenomenología que avanza hacia la consideración de la subjetividad trascendental que debe ser investigada para resolver las dificultades que supone el problematizar cómo aquello irreductible a lo psicológico puede darse a la conciencia y hacerlo en el tiempo de la conciencia. El modelo de la intencionalidad en la explicación del conocimiento así como la epojé y la reducción demuestran que no es necesario ese compromiso realista de la idealidad para que el proyecto de la fenomenología continúe por los derroteros de radicalidad marcados. Por eso, en mi opinión, la función que tiene el realismo eidético para desvincular a la razón de toda intromisión relativista y escéptica, es la que sigue presente y resulta reasumida por los puntales de la fenomenología trascendental. Y es que, por mucha crítica al psicologismo tal y como aparece en Prolegómenos, no puede negarse que los números o las significaciones se dan a un sujeto. Y que es precisamente el darse, la fenomenicidad de todo fenómeno, lo que ofrece el dato incontrovertible. Un darse que es, a la vez, la manera de correlacionarse con la subjetividad que apunta hacia una concepción de la objetividad distinta de la idealidad con tintes platonizantes, sin que esto implique una recaída en el psicologismo ferozmente criticado por la fenomenología. No se trata de despedirse de los eide cuanto de observar cómo se reordena la cuestión de la objetividad en el contexto de los problemas que deben ser abordados en las distintas fases del pensamiento husserliano en Gotinga o en Friburgo. Por ejemplo, cuando en la Crisis Husserl ponga de manifiesto otra concepción eidética del lenguaje (creo que puede denominarse así siempre que ello no nos obligue a pensar en los términos de la idealidad de la I Investigación) la objetividad ya no será tanto un presupuesto cuanto un resultado, lo que, como venimos insistiendo, no es un corte con el planteamiento anterior sino la más estricta coherencia de la fenomenología.

"Un resultado del hacer humano y de la fijación lingüística del mismo, ya que el lenguaje permite la sedimentación cultural de los resultados del desarrollo activo de la vida intramundana de la humanidad y evita que la evidencia original de los mismos dependa de la imposible existencia de un diálogo siempre actual en el que dicha evidencia pudiera verse constantemente reproducida". ${ }^{87}$

En su trabajo Sobre el origen de la geometría ${ }^{88}$ Husserl profundiza en el proceso abstractivo que va desde el mundo de la vida al descubrimiento de las esencias que, siendo verdades objetivas cuyas evidencias fueron asequibles para todos los pueblos y culturas, se establecen por medio del lenguaje que permite asegurar la permanencia de las significaciones ideales de esta ciencia. Esto no significa que el lenguaje produzca tales objetos ideales como si de cualquier otro producto cultural se tratara. Ocultar el justo papel del lenguaje es, a su vez, encubrir y desatender al proceso vital, preteorético e intersubjetivo del origen, en este caso, de la geometría. Todo un proceso que tiene su culmen en la formalización e idealización de la naturaleza por parte de Galileo que confunde la distancia entre lo ideal y lo real obviando el papel de la abstracción eidética como proceso.

16, 1997, pp. 101-121. De la cita, p. 110

87 Lerin Riera, J. "Lenguaje e idealidad” Anales del seminario de historia de la filosofia, 25, 1991, pp. $195-210$. De la cita, p. 208.

${ }_{88}$ El texto fue escrito en 1936 y publicado primero por E. Fink en 1939 y después recogido como Apéndice III de Die Krisis en el vol. VI de la Husserliana. La versión castellana utilizada ha sido traducida por J. Arce y R. Rizo-Patrón en Estudios de Filosofía, IV, 2000, pp. 35-54. 
La crisis europea hunde aquí sus raíces, precisamente en olvidar que estos procesos matematizantes, que esos métodos científicos son sólo instrumentos constituidos por seres humanos finitos cuyos resultados están bien lejos del carácter estricto que debe tener la ciencia. La tarea de la fenomenología, tal y como queda recogida en La crisis de las ciencias europeas, consiste en recuperar el sentido originario de esos objetos ideales para poder encarrilar la ciencia al suelo del mundo de la vida, al ámbito de los horizontes de vida compartidos. ${ }^{89}$ Se trata, pues, de recuperar la historia interna constituida por dichas esencias, esto es, por los sentidos ocultos tras un inmenso ropaje de idealizaciones y de formalizaciones y volver así al acto fundacional que les dio origen recobrando su sentido primigenio. ${ }^{90} \mathrm{El} \mathrm{radicalismo} \mathrm{husserliano} \mathrm{tiene}$ su más profunda motivación en esta aspiración a profundizar hasta las raíces, hasta los últimos fundamentos del conocer. ${ }^{91}$ Es la nueva faz de un radicalismo de la razón que ahora ya no toma cuerpo en el ideal epistémico de apodicticidad que, en cuanto la imposible cabida del error, deja de ser el objetivo prioritario de los otros caminos a la fenomenología distintos al camino cartesiano.

\section{Referencias bibliográficas}

Bar-Hillel, Y. "Husserl's conception of a purely grammar". Philosophy and Phenomenological Research, 17, 1957, pp. 362-369.

Biemel, W. "Las fases decisivas del desarrollo de la filosofía de Husserl". En Husserl. Tercer Coloquio Filosófico de Royaumont, Buenos Aires: Paídós, 1968, pp. 35-67

Castilla Lázaro, R. Zur Husserls Sprachphilosophie und ihren Kritikern. Berlin: Diss, 1967.

Derrida, J. La voix et le phénomène. Introduction au problème du singe dans la phénoménologie de Husserl. Paris: Quadrige/PUF, 1998.

Derrida, J. La fenomenología y la clausura de la metafísica. Introducción a Husserl, Edición digital de Derrida en castellano, 2008. (Fecha de consulta, noviembre 2014).

Diana Cohen, E. "Las idealidades matemáticas: historia y sentido. Una reflexión en torno a ciertas dificultades del programa del último Husserl" Themata. Revista de Filosofia, 21, 1999, pp. 69-84.

Díaz, C. "La teoría de la significación en Husserl". Logos. Anales del seminario de metafísica, 4, 1969, pp. 41-58.

Fernández Beites, P. "La evidencia pre-predicativa. Apodicticidad como adecuación" en A. Serrano de Haro (ed.), La posibilidad de la fenomenología. Madrid: Ed. Universidad Complutense, 1997, pp.13-37.

89 En realidad, esto es lo que Husserl quiere decir en La Crisis con el término 'humanidad': la configuración de un mundo de carácter común, de una conciencia común (Gemeinschaftsbewusstsein). En definitiva un mundo que se configura como un horizonte común de cosas existentes realmente.

90 E. Diana Cohen indica que este procedimiento implicaría una actividad sobre los distintos estratos de formación y de sedimentación de las construcciones culturales, incluidos los objetos ideales, que "por el hecho de estar inmersas en la historia, atraviesan por un movimiento de institución, sedimentación, reactivación y transformación de su sentido”. Diana Cohen, E. "Las idealidades matemáticas: historia y sentido. Una reflexión en torno a ciertas dificultades del programa del último Husserl" Themata. Revista de Filosofía, 21, 1999, pp. 69-84. De la cita, p. 78. Lo que sucede es que la estructura temporal de la conciencia vuelve compleja toda indagación del sentido original. La dificultad de tal hazaña es lo que le hace a Husserl escribir sobre la dificultad de comprender el sentido primigenio a partir de la forma actual de la ciencia cuyo desarrollo, a su vez, sin una correcta comprensión de los comienzos, es nulo de sentido.

91 "Porque efectivamente, la transformación del Husserl matemático en el fenomenólogo trascendental genéticoconstitutivo es el resultado de una línea evolutiva directa que parte de ese desasosiego inicial suyo ante la crisis de la matemática." García Prada, p. 50 
García Baró, M. “La filosofía primera de E. Husserl en torno a 1900” Dianoia, 32, 1986, pp. 41-69.

García Norro, J. J. "La respuesta husserliana en las Investigaciones Lógicas a la aporía del antropologismo." Logos. Anales del seminario de metafísica, 27, 1993, pp. 127-135

García Prada, O. "La fundamentación de la matemática y la génesis de la metódica fenomenológico-reductiva". Anales del Seminario de Historia de la Filosofía, vol. 6, 2, 1986, pp. 47-78.

Husserl, E. La filosofía como ciencia estricta. La Plata: Terramar, 2007.

Husserl, E. Ideas relativas a una fenomenología pura y una filosofía fenomenológica. Madrid: FCE, 1993.

Husserl, E. La idea de la fenomenología. Madrid: FCE, 2004.

Husserl, E. Studien zur Arithmetik und Geometrie. Texte aus den Nachlaß (1886-1901). La Haya: M. Nijhoff, 1986.

Husserl, E. Über den Begriff der Zahl. Psycologische Analysen. Halle a. S.: Heynemann'sche Buchdruckerey (F. Beyer), 1887.

Husserl, E. Formale und transzendentale Logik. Versuch einer Kritik der logischen Vernunft. The Hague, Netherlands: Martinus Nijhoff, 1974. Versión castellana, Lógica formal y lógica trascendental. Traducción de Luis Villoro. México: UNAM, 1962.

Husserl, E. Logische Untersuchungen. The Hague, Netherlands: Martinus Nijhoff, 1984. Versión castellana, Investigaciones Lógicas. Traducción de Manuel G. Morente y José Gaos. Madrid: Alianza, 2011.

Husserl, E. Meditaciones cartesianas. Traducción de Mario Presas. Madrid: Tecnos, 2009.

Husserl, E. Renovación del hombre y de la cultura. Madrid: Anthropos, 2012.

Lerin Riera, J. "Lenguaje e idealidad" Anales del seminario de historia de la filosofia, 25, 1991, pp. 195-210.

Levinas, E. La teoría fenomenológica de la intuición. Salamanca: Sígueme, 2004.

Landgrebe, L. "Zur Überwindung des europäischen Nihilismus. Der Nihilismus als Phänomen des Geistesgeschichte in der wissenschaftlichen Diskussion unseres Jahrhunderts”, en Arendt, D., Der Nihilismus als Phänomen der Geistesgeschichte in der wissenschaftlichen Diskussion unseres Jahrhunderts. Darmstadt: Wissenschaftliche Buchgesellschaft, 1974.

Rizo-Patrón, R. "Objetividades matemáticas, ¿reales o ideales? Reflexiones desde el pensamiento de E. Husserl”, en Areté. Revista de Filosofía, vol. 24, 2012,1, pp. 181-201

Rizo-Patrón, R. "Génesis de las Investigaciones lógicas de Husserl: una obra de irrupción”. Signos Filosóficos, 7, 2002, pp. 221-244.

Rossi, A. "Sentido y sinsentido en las Investigaciones Lógicas" Dianoia, 6, 1960, pp. 91114.

San Martín, J. “La despedida de Husserl del cartesianismo según Landgrebe.” Ágora. Papeles de Filosofia, 16, 1997, pp. 101-121.

San Martín, J. La nueva imagen de Husserl. Lecciones de Guanajuato. Madrid: Trotta, 2015. Serrano de Haro, A. Paseo filosófico en Madrid. Madrid: Trotta, 2016.

Zubiri, X. Cinco lecciones de filosofía. Madrid: Sociedad de Estudios y Publicaciones, 1963. 